\title{
Sobre os Katxuyana e Kahyana
}

\author{
Adriana Russi* \\ Denise Fajardo **
}

RUSSI, A.; FAJARDO, D. Sobre os Katxuyana e Kahyana. R. Museu Arq. Etn. 37: 20-23, 2021.

Resumo: Breve apresentação sobre quem são os Katxuyana e Kahyana no contexto dos demais povos/yanas, histórica e atualmente vizinhos entre si, na região dos rios Cachorro e Trombetas, norte do Pará.

Palavras-chave: Katxuyana; Kahyana; Yanas; Karib; Guianas.

Os: Katxuyana são moradores tradicionais do rio Katxuru (ou Cachorro), e os Kahyana, do rio Kahu (ou Trombetas), na altura dos rios Kuhá e Kaspakuro. Ambos os grupos são falantes de línguas pertencentes à família linguística Karib, assim como os demais povos (ou yanas) vizinhos do interior dessa região, também conhecida como Grande Guiana ou Escudo das Guianas.

Desde fins do século XIX, não apenas os Katxuyana e Kahyana, mas praticamente todos os demais yanas mencionados em fontes documentais e de pesquisa etnográfica sobre a região foram registrados com diferentes grafias, por exemplo, Kashuièna e Kaciana, entre outras, para o caso dos Katxuyana (esta última correspondendo à forma como, recentemente, eles próprios convencionaram grafar seu etnônimo). Essas diferenças, por vezes, dificultam sua identificação em algumas fontes, textos, coleções etnográficas, dentre outros documentos.

Outra dificuldade relacionada à identificação e delimitação desses yanas (quem

* Docente da Universidade Federal Fluminense e do Programa de Pós-Graduação em Memória Social da Unirio. <adri.russitm@gmail.com>

** Coordenadora do Programa Tumucumaque do Instituto de Pesquisa e Formação Indígena (Iepé). <denise@institutoiepe.org.br> são, exatamente, os Katxuyana e os Kahyana e assim por diante) diz respeito ao caráter sempre plural da composição de cada povo, e também ao fato de que é quase impossível, para não dizer completamente impossível, que encontremos uma pessoa ou aldeia que seja integralmente composta por um único yana - uma pessoa que possa dizer que descende unicamente de pais e avós de origem ou Katxuyana, ou Kahyana; ou, ainda, uma aldeia formada unicamente apenas por pessoas de origem Katxuyana ou Kahyana.

Assim, o que é possível afirmar de saída é que, tal como eles próprios se definem ao dizer "somos misturados", os Katxuyana e os Kahyana só podem ser compreendidos no contexto da sociodiversidade da qual fazem parte, enquanto Katxuru-yana (gente do rio Katxuru) e enquanto Kah[u]-yana (gente do rio Kahu). Como é possível observar, seja nos textos históricos que este dossiê traz à luz em português, seja no presente, esses dois yanas não apenas mantêm relações de vizinhança e parentesco entre si, como também nutrem histórica e atualmente essas mesmas relações com outros yanas, ainda que isso seja pouco mencionado nas fontes disponíveis, principalmente para o período que vai de 1960 a 1990. Isso se explica em função de algumas circunstâncias da época que terminaram por 
colocar os Katxuyana e, sobretudo, os demais yanas dessa região - inclusive os Kahyana - em uma zona de invisibilidade que ainda hoje é difícil de romper.

Para o período que vai até a década de 1960, encontramos em Classificação Lingüísticoetnológica das Tribos do Pará Setentrional e Zonas Adjacentes, uma obra emblemática de Protásio Frikel (1966a), os resultados de um levantamento com o registro do impressionante número de 144 "tribos" indígenas vivendo em mais de 100 aldeias no extremo norte do Pará. Em meio a este levantamento encontravam-se os Katxuyana e Kahyana, mas não só, identificados nas regiões do interflúvio Trombetas-Cachorro, juntamente com outros mais:

- Itchitchwáyana

- Yaskuriyana

- Urumanányana

- Kachpakúyana

- Wayarama

- Pawiyana

- Kuháyana

- Ingarüne (Tchikaridjana)

- Prëhnoma do rio Cachorrinho

Os membros dessas chamadas "tribos" viviam envolvidos em intensas redes de relações e amplos circuitos de trocas, que se concretizavam por meio de viagens frequentes, a pé ou de canoa, pela malha de estreitos rios e igarapés que recobre a região. Porém, nessa mesma época, uma série de incursões exploratórias avançaram por todo o interior da tríplice fronteira entre o extremo norte do Pará, a Guiana e o Suriname, e a falta de imunidade às doenças infectocontagiosas que assolaram a região nessa época desencadeou epidemias e altas taxas de mortalidade indígena. Tal combinação resultou, por um lado no desaparecimento físico de alguns destes yanas que Frikel chegou a registrar, e possivelmente de outros cujo registro não chegou a ser feito, como os Txikiyana, mencionados em fontes orais mais recentes. Por outro lado, os sobreviventes dessas doenças encontraram-se diante de várias alternativas de ajuda vindas dos governos dos três países (Brasil, Guiana,
Suriname), todas vinculadas a missões religiosas com permissão para atuarem na região, instalando aldeias-sedes que funcionavam como "bases de atração". No caso brasileiro, essas aldeias foram instaladas em quatro pontos do norte do Pará, a saber: Kassawá e Mapuera (na atual Terra Indígena Nhamundá/Mapuera); Bona e Missão Tiriyó (na atual Terra Indígena Parque do Tumucumaque).

No bojo desse processo de aglutinação de vários yanas em torno de aldeamentos missionários ocorre o fenômeno responsável pela rápida invisibilização da diversidade de nomes e povos antes existente nessa região. É assim que a população indígena dos rios Cachorro e médio Trombetas passa a ser reconhecida predominantemente como Katxuyana nos lugares para onde se desloca, mesmo que em seus territórios de origem, de onde partiram nos anos 1960 em busca de sobrevivência, se considerassem como Yaskuriyana, Kahyana, Ingarinyana, Txikiyana, dentre outros yanas. Concretamente, alguns familiares de origem predominantemente Katxuyana, Yaskuriyana e Kahyana rumaram para a aldeia Kassawa, no rio Nhamundá, junto à missão do Summer Institute of Linguistics (SIL) ali instalada, e ali ficaram conhecidos genericamente Katxuyana.

Alguns anos mais tarde, esse grupo fundou uma aldeia própria e estreitou relações com a população do baixo Nhamundá, principalmente por conta do comércio da castanha. Outro grupo de sobreviventes dos rios Cachorro e Trombetas, hoje, se refere ao dia 23 de fevereiro de 1968, como um marco - "o dia mais triste de nossas vidas", como definiu um importante líder de origem Katxuyana e Ingarïne -, quando juntamente com parentes e vizinhos de origem Kahyana, Txikiyana e outras se viram dali transportados em uma aeronave da Força Aérea Brasileira (FAB) para a aldeia Missão Tiriyó, localizada na faixa oeste do Complexo Tumucumaque, deixando para trás seus pertences e suas histórias, em busca da assistência médica somente oferecida longe dali.

Da mesma forma, os povos Tunayana, Katuwena e Xerew, dentre outros, também se viram obrigados a migrar para grandes 
aldeias-sede de bases missionárias, entre as décadas de 1950 e 1970, como Kanashen, na então Guiana Inglesa, ou Tëpu e Kuwamara, no Suriname, em busca de salvar suas vidas. Mesmo assim, alguns dentre os diversos yanas dessa região, hoje reconhecida como Terra Indígena Kaxuyana-Tunayana, decidiram lá permanecer, isolando-se voluntariamente do contato para se proteger, vivendo assim até os dias de hoje. Os demais yanas, não se desligando por completo de seus territórios de origem, nunca pararam de voltar e reocupá-los ao longo dessas cinco décadas. Desse modo, este território tradicional nunca foi abandonado ou desocupado completamente por seus povos originários, que também nunca deixaram de sonhar com a regularização. Em 2003, puderam formalizar essa demanda junto à Fundação Nacional do Índio (Funai) e em 2018, finalmente, após exatos 50 anos da remoção para o Tumucumaque, houve a publicação da portaria que reconheceu esta Terra Indígena, emitida pelo Ministério da Justiça.

De volta aos seus locais de origem, aqueles que na Missão Tiriyó e no rio Nhamundá eram conhecidos como "os Kaxuyana" então refundam suas aldeias ao longo dos rios Cachorro e Trombetas, se reencontrando novamente consigo mesmos enquanto diferentes yanas que sempre foram.

Numa das aldeias do rio Cachorro, os Katxuyana reconstruíram, no ano de 2010, um tipo de casa comunal denominada tamiriki. Desde então, em outras aldeias da região, mais tamirikis continuaram a ser reerguidas. Nessas casas fazem suas festas, cerimônias e reuniões, durante as quais se utilizam de vários artefatos, dentre eles um adorno plumário denominado txamatxama. Muitos desses artefatos estão abrigados em museus na Europa e no Brasil e são descritos em algumas publicações originalmente publicadas em alemão, agora traduzidas para o português e incorporadas à presente publicação.
Em outra aldeia, às margem do rio Kaspakuro, em 2018, os Kahyana celebraram sua existência e a retomada do território tradicional às margens do Trombetas com uma grande e significativa festa tradicional, após terem sido descritos como "em processo de extinção enquanto povo” (Frikel 1966b) e dados por extintos de fato, quando na verdade, estavam e, de certa forma, ainda continuam invisibilizados pelo olhar do Estado e da sociedade em geral.

O entorno dos rios Trombetas e Kaspakuro corresponde ao local onde os Kahyana têm e sempre tiveram suas moradias, roças, sítios de caça e pesca, lugares sagrados, mitologia, enfim, onde construíram sua especificidade étnica e cultural. Seu território não se confunde com outros existentes no interior da Terra Indígena Katxuyana-Tunayana, de ocupação tradicional de outros povos e culturas, como os Katxuyana, Yaskuriyana, Xereu, Katuena, Hixkariyana e Tunanaya. Viram-se ameaçados desde a década de 1970, mas nunca abandonaram totalmente sua área de perambulação no interior da Terra Indígena Katxuyana-Tunayana, e no final dos anos 1990, os Kahyana voltaram a retomar seu território tradicional nos rios Kahu e Kaspakuro, refundando ali três das inúmeras aldeias que antes existiam.

Neste sentido é que esta publicação, ao mesmo tempo que homenageia aos Katxuyana com os textos disponibilizados, também ressalta a impossibilidade de falar sobre quem eles são sem abordar também quem são os Kahyana e todo o arquipélago de yanas no qual estão inseridos. É necessário lembrar também, seguindo a metáfora usada por Viveiros de Castro (2020), de que "Aucun peuple n'est une île", ou seja, "nenhum yana é uma ilha", por isso a importância hoje da Terra Indígena Kaxuyana-Tunayana não apenas enquanto território de direito conquistado, mas como a Casa que sempre abrigou e continuará abrigando a rica sociodiversidade dos yanas Karib-guianenses. 
RUSSI, A. FAJARDO, D. About the Katxuyana and the Kahyana people.

R. Museu Arq. Etn. 37: 20-23, 2021.

Abstract: This article gives a brief presentation on who the Katxuyana and Kahyana are as to other peoples/yanas, historically and currently neighbors to each other, in the region of the Cachorro and Trombetas rivers, northern Pará.

Keywords: Kaxuyana; Kahyana; Yanas; Karib; Guyana.

\section{Referências bibliográficas}

Frikel, P. 1966a. Classificação lingüístico-etnológica das tribos indígenas do Pará setentrional e zonas adjacentes. Revista de Antropologia 6: 113189.

Frikel, P. 1966b. Os últimos Káhyana. Revista do Instituto de Estudos Brasileiros 1: 734.
Viveiros de Castro, E. 2020. "Aucun peuple nest une île". Les peuples 'isolés' en Amazonie contemporanie. In: Cometti, G. et al. (Ed.). Au seuil de la forêt. Hommage à Philippe Descola, lanthropologue de la nature. Tautem, Paris, 1063-1080. 